\title{
Pattern of Substance Abuse in Patients Attending Psychiatry OPD of IGMC, Shimla
}

\author{
Dr. Parul Sharma, Anita Thakur. \\ Department of Psychiatry, Maharishi Markandeshwar Medical College and Hospital, Kumarhatti, Solan (H.P.).
}

Abstract: Substance abuse has become one of the major contributor to psychiatric morbidity worldwide. The pattern of substance abuse, in patients attending psychiatry OPD of IGMC, Shimla, from the years 2006 to 2008, was studied. Alcohol abuse was found to be the most prevalent, followed by that of cannabis. Opioid, sedative and inhalant abuse trends were found increase over these years.

Key Words: Alcohol abuse, cannabis abuse, opioid abuse, tobacco, sedative and multiple substance abuse.

\section{Introduction:}

Man has been using plant derived drugs and alcohol for thousands of years. The earliest reference to the intoxicating properties of certain cannabis preparation is found in the Atharva Veda, a religious text believed to date from 2000-1400 BC. ${ }^{1}$

One of the objectives of the United Nations International Drug Control Programme is to improve the quality and comparability of country - specific drug abuse data by developing an information infrastructure in some 100 countries. The Annual Reports Questionnaire (ARQ) is used to gather information from various international and regional organizations, research institutes, and epidemiology networks. Based on the most recent data collected, it is estimated that:

- Around 8 million people abuse opiates / heroin, mostly in South East and South West Asia. Heroin abuse is far more wide-spread than it was a decade ago. Sharp increases have been reported in former Soviet Union countries. Increases also have been reported in Iran, Turkey, and Pakistan. Heroin has remained readily available in major metropolitan areas in the United States.

- Some 13 million people abuse cocaine worldwide, with the highest prevalence reported in the United States. Many Latin American countries also have high levels of cocaine and bazuco (coca paste) abuse. In the 1995 to 1997 period, cocaine abuse spread in Europe and was stabilized in the main markets of North America. Increases have been reported in the Andean and neighboring countries and along trafficking routes to America and Europe.

- 141 million people consume cannabis annually. It is the most widely abused drug in all parts of the world. Cannabis abuse is particularly high in western Africa, Oceania, Central America, North America, and a number of European countries. ${ }^{2}$

Objective: To study the pattern of substance abuse in patients attending psychiatry OPD of IGMC, Shimla.(HP)

\section{Observations}

The pattern of substance abuse among the patients attending psychiatry OPD of IGMC, Shimla, was studied in the years 2006, 2007, 2008. The pattern is shown in the tabular as well as pie chart form for the above mentioned years.

- Distribution Of Patients (Outdoor) By Type Of Substance Abuse In The Year 2006.

\begin{tabular}{lll} 
Substance & $\mathbf{N}$ & $\mathbf{\%}$ \\
\hline Alcohol & 153 & 68.30 \\
\hline Opioids & 11 & 4.91 \\
\hline Cannabis & 33 & 14.73 \\
\hline Inhalants & 10 & 4.46 \\
Sedatives & 2 & 0.91 \\
Tobacco & 7 & 3.12 \\
Multiple & 8 & 3.57 \\
Total & 224 & 100
\end{tabular}

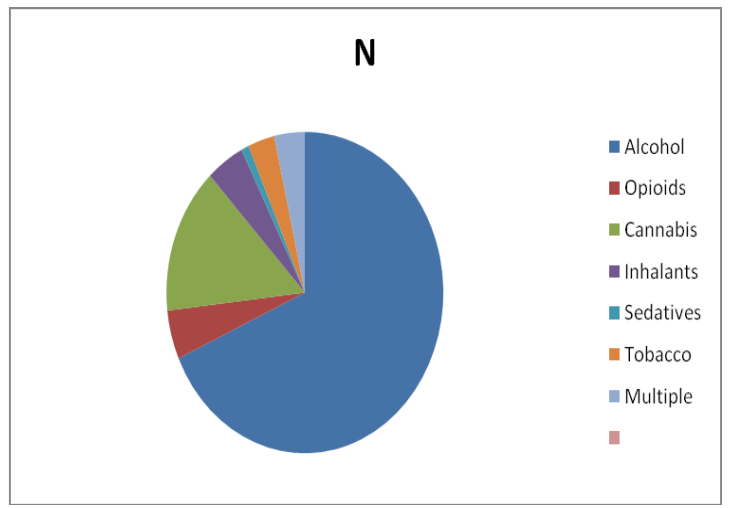


- Distribution Of Patients (Outdoor) By Type Of Substance Abuse In The Year 2007.

\begin{tabular}{lll} 
Substance & $\mathbf{N}$ & $\mathbf{\%}$ \\
\hline Alcohol & 162 & 67.78 \\
Opioids & 13 & 5.43 \\
Cannabis & 35 & 14.6 \\
Inhalants & 12 & 5.02 \\
Sedatives & 1 & 0.49 \\
Tobacco & 6 & 2.50 \\
Multiple & 9 & 4.18 \\
Total & 239 & 100
\end{tabular}

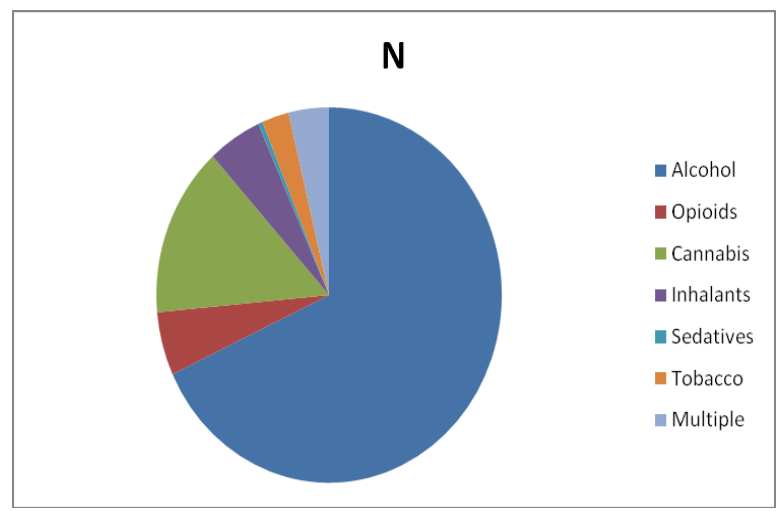

- Distribution Of Patients (Outdoor) By Type Of Substance Abuse In The Year 2008.

\begin{tabular}{|l|l|l|}
\hline Substance & $\mathbf{N}$ & $\mathbf{\%}$ \\
\hline Alcohol & 206 & 66.02 \\
\hline Opioids & 22 & 7.05 \\
\hline Cannabis & 43 & 13.78 \\
\hline Tobacco & 14 & 4.49 \\
\hline Inhalants & 7 & 2.24 \\
\hline sedatives & 8 & 2.56 \\
\hline Multiple & 12 & 3.96 \\
\hline Total & 311 & 100 \\
\hline
\end{tabular}

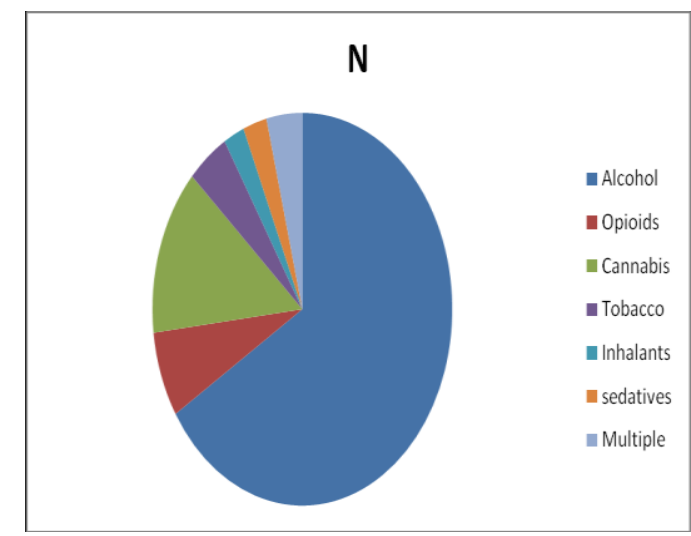

- $\quad$ Age Wise Distribution Of Patients (Outdoor) By Type Of Substance In 2008



\section{Discussion}

The pattern of substance abuse in patients attending psychiatry OPD of IGMC Shimla in the years 2006, 2007, 2008 showed that, the maximum substance abuse was alcohol $(68.30 \%, 67.78 \%, 66.02 \%$ respectively). This was followed by cannabis abuse $(14.73 \%, 14.6 \%$, and $13.78 \%$ respectively). Opioid abuse was $4.91 \%, 5.43 \%$, $7.05 \%$ respectively; followed by inhalant abuse prevalence was $4.46 \%, 5.02 \%, 2.24 \%$. Tobacco abuse was $3.12 \%, 2.50 \%, 4.49 \%$; and multiple substance abuse was $3.57 \%, 4.18 \%$ and $3.96 \%$. Least of all was sedative abuse which was found to be $0.91 \%, 0.49 \%$ and $2.56 \%$ in the years $2006,2007,2008$.

Thus, over the years alcohol, cannabis and multiple substance abuse remain almost the same, while opioid, tobacco and sedative abuse increased slightly over these years. Inhalant abuse, on the other hand, was found to decrease in the year 2008 . 
Similar to the findings in our study, alcohol abuse had maximum prevalence in the epidemiological study on a sample of 2,264 individuals (male, 1,033; female, 1,231) aged 15 years and older in 2002-2003 in a tea garden population of Assam. The total age-adjusted prevalence of alcohol consumption was $59.2 \%$ (male, $69.3 \%$; female, 54\%). More than half of the respondents (54.7\%) were multiple users of alcohol and tobacco. Prevalence of alcohol consumption in the 15-24 year age group was $32.2 \%{ }^{3} \mathrm{~A}$ recent estimate from surveillance of major noncommunicable diseases in India placed the burden due to alcohol as the numero uno among all noncommunicable disorders. ${ }^{4}$

Findings of our study in the year 2008, showed that, among patients attending OPD of IGMC Shimla, alcohol abuse was most common in the age group of 40 to 49 years; cannabis 20 to 29 years, opioid 30 to 39 years, inhalant 10 to 19 years, sedative 50 to 59 years, multiple substance abuse remained same in all age groups. Maximum alcohol abuse, however, was found in earlier age groups in the study conducted by Meena et al. in a selected population of above 14 years males in Rohtak city, which found that the prevalence of alcohol use was $19.78 \%, 42.4 \%$ were in age group of $25-34$ years followed by $28.01 \%$ in age group of $35-44$ years. $94.83 \%$ respondents had their first drink between the ages of 15-25 years. Frequency of opium and cannabis abuse came out to be $1.51 \%$ and $1.18 \%$ respectively. ${ }^{5}$ That alcohol use was maximum in age group $25-34$ years, was also reported by Jeena et al. (1996) ${ }^{6}$ and Bhowmick et al. $(2001)^{7}$

Inhalant abuse was found more in young adults in the years 2006 to 2008, which is comparatively more than found in previous years. Products containing aliphatic and aromatic hydrocarbons and halogenated hydrocarbons are among the common sources of volatile substances that are abused. Experimentation with these agents among younger adolescents is a common practice seen globally in last decades. ${ }^{8}$ Although, the first case series of petrol inhalation dependence from India was published more than 25 years ago, there have been sporadic case reports (4-6) and occasional case series in recent years that suggest in addition to other substances, particularly type writer correction fluids, gasoline and other volatile hydrocarbons, might be increasing ${ }^{9,10}$ In a study by Basu D. et al., it was found, that most of the patients started inhalant abuse in early adolescence before shifting to other substances. ${ }^{11}$ All of the patients, except one, reported using inhalants as first addictive substance, because of their easy accessibility, cheap price, faster onset and regular "high" that it produced. ${ }^{12}$

Study by Hazarika et al. to study the prevalence and pattern of substance abuse in a selected population of 10 years and above, found that, prevalence of tobacco use was $40.4 \%, 36.5 \%$ among the respondents were alcohol users. Other substance abuse was found to be $3.4 \%$. Out of them, $1.28 \%$ had injectable drug use, $0.64 \%$ had petrol inhalation, $61.9 \%$ of tobacco users started taking tobacco before age of 20 years. $49.1 \%$ of alcohol users started taking alcohol before they attained age of 20 years and more than $50 \%$ of the users started taking alcohol after age of 20 years. Substance abusers other than tobacco and alcohol started using drugs before 20 year age. ${ }^{13}$ Our findings of tobacco abuse prevalence in the years 2006 to 2008 were lower than that in above study $(3.12 \%$, $2.50 \%, 4.49 \%$ ). The probable reason for the above, could be due to the fact, that the patients of tobacco dependence alone, did not come up for the treatment in the OPD in as large a number as expected, although tobacco abuse is quite common in this community.

\section{Conclusion}

The pattern of substance abuse in patients attending psychiatry OPD of IGMC, Shimla in the years 2006, 2007 and 2008 showed that, maximum prevalence was that of alcohol, followed by cannabis and opioid. Inhalant, sedatives and multiple substance abuse, varied slightly over these above mentioned years. Prevalence of tobacco abuse, however, was found in the lower range, compared to other studies, which could be attributed to the fact that, very few of these abusers, from the community came to the OPD to seek deaddiction for tobacco. Maximum alcohol abuse was found in the age group 40-49 years, while cannabis and inhalant abuse was more common in earlier age group (20-29 years, 10-19 years respectively).

\section{Acknowledgement:}

We are sincerely thankful to Dr. Ramesh Sharma, Department of Psychiatry, IGMC Shimla, for his help in the study.

\section{References}

[1]. Basu D. and Mattoo S.K.: Epidemiology of substance abuse in India: Methodological issues and future perspectives. Indian Journal of Psychiatry, 1999, 41(2), 145-153.

[2]. Epidemiologic Trends in Drug Abuse: Advance Report, June 1999. Community Epidemiology Work Group. National Institutes of Health, National Institute on Drug Abuse.

[3]. Gururaj G., Rao G.N., Bengal V., Murthy P.: Alcohol use and public health: the Indian perspective. National Institute of Mental Health and Neurosciences Bangalore, India, for World Health Organization, 2006.

[4]. Anand K.: Assessment of burden and surveillance of major noncommunicable diseases in India. World Health Organization(WHO) South East Asia Regional Office, workshop document: New Delhi 2000

[5]. Meena, Khanna P., Vohra A.K., Rajput R.: Prevalence and pattern of alcohol and substance abuse in urban areas of Rohtak city. Indian Journal of Psychiatry, 2002, 44(4) 348-352. 
[6]. Jena R., Shukla T.R. and Hemraj P. (1996): Drug use in a rural community in Bihar: some psychosocial correlates. Indian J of Psychiatry. 38 (1), 43-46.

[7]. Bhowmick P., Tripathi B.M., Jhingan H.P. and Panday R.M. (2001): Social support, coping resources and co-dependence in spouses of individuals with alcohol and drug dependence. Indian Journal of Psychiatry, 43(3), 219-224.

[8]. Flanagan R.J., Ives R.J.: Volatile substance abuse. Bull Narc 1994; 46: 49-78.

[9]. Beauvais F., Oetting E.R.: Inhalant abuse by young children. In Crider R.A., Rouse B.A., (Ed),. Epidemiology of inhalant abuse: An Update. NIDA monograph 3033. Rockville M.D.: National Institute on Drug Abuse, 1988: 1-203.

[10]. Shah R., Vankar G.K., Upadhyaya H.P.: Phenomenology of gasoline intoxication and withdrawal symptoms among adolescents in India: A case series. Am J Addict 1999; 8; 254-7.

[11]. Basu D., Ihirwal O.P., Singh J., Kumar S., Matoo S.K.: Inhalant abuse by adolescents: A new challenge for Indian physicians. Indian J Med Sci Vol58 No 6, June 1004

[12]. Waraich B.K., Chavan B.S., Raj L.: Inhalant abuse: A growing public health concern in India. Addiction 2003; 98:1169.

[13]. Hazarika N.C., Biswas D., Phukan R.K., Hazarika D. and Mahanta J.: Prevalence and pattern of substance abuse at Bandardewa, a border area of Assam and Arunachal Pradesh. Indian Journal of Psychiatry, 2000, 42(3) 262-266. 